\title{
THERMODYNAMICS OF SOLUTIONS OF HYDROCARBONS IN LOW MOLECULAR WEIGHT POLY(ISOBUTYLENE). A GAS CHROMATOGRAPHIC STUDY
}

\author{
TERMODINAMICA DE SOLUCIONES DE HIDROCARBUROS EN POLI(ISOBUTILENO) \\ DE BAJO PESO MOLECULAR. UN ESTUDIO POR CROMATOGRAFIA GASEOSA
}

\author{
R.C. Castells ${ }^{1}$, L.M. Romero ${ }^{2}$ and A.M. Nardillo ${ }^{1}$
}

\begin{abstract}
SUMMARY
The reduced chemical potentials $\left(\chi^{*}\right)$ of twenty normal and branched alkanes, cyclohexane and three aromatic hydrocarbons at infinite dilution in polyisobutylene $(P I B)$ were measured by gas-liquid chromatography at five temperatures between 35 and $65^{\circ} \mathrm{C}$. Reduced partial molar residual enthalpies ( $\left.\mathrm{K}^{*}\right)$ were calculated from the temperature dependence of $\chi^{*}$; they are positive for PIB+alkane systems, but smaller than those obtained in former chromatographic studies. Although uncertainties on $\mathrm{K}^{*}$ are at least one order of magnitude larger than those on $\chi^{*}$, binary $\mathrm{x}_{12}$ Flory parameters obtained from $\kappa^{*}$ display a good correlation with the structural parameter $\theta_{\mathrm{ev}}$ defined as the ratio of the number of hydrogen atoms on methyl groups to the total number of hydrogen atoms in the alkane molecule. Very poor or nil correlation exists between $\mathrm{X}_{12}$ values obtained from $\chi^{*}$ and $\theta_{\mathrm{e} 1}$. The evidence is by no means conclusive, but in principle the $\chi^{*}$ results obtained for PIB + alkane systems could be explained in terms of free volume contributions and of the antipathy between methyl groups on the alkanes molecules and the polymer side groups. Positive partial molar residual entropies were detected for the three aromatic hydrocarbons; their partial molar residual enthalpies are however highly positive, resulting in their poor solvent properties towards $P I B$.
\end{abstract}

Keywords: Poli(isobutileno), hidrocarburos, termodinámica, cromatografía gaseosa, soluciones de polímeros, Modelo de Flory.

\section{INTRODUCTION}

Notwithstanding that many years have passed since its conception, Flory theory $[1,2]$ is probably still the most useful interpretative framework for the discussion of the thermodynamic properties of non-electrolyte mixtures. The theory recognizes three contributions to the mixing

\footnotetext{
1 Miembro de la Carrera del Investigador del CONCET, UNLP

2 Division Qúmica Analítica, Facultad de Ciencias Exactas, UNLP
} 
functions: combinatorial, free volume and interactional; they were reviewed in a recent paper [3].

The theory has been most usually checked against calorimetric results; the interactional contribution is obtained by deducting the free volume contribution (calculated from equation of state data of the pure components by means of Flory's equations) from the excess enthalpy, $\mathrm{HE}^{\mathrm{E}}$. The interactional contribution is characterized by the $\mathrm{X}_{12}$ parameter, that denotes the energy change for formation of of contacts between species 1 and 2 in exchange for contacts between like species; according with the theory $X_{12}$ is temperature and concentration independent. Another way of approach has been the measuremente of excess free energies, $\mathrm{G}^{\mathrm{E}}$, by osmometric methods, by vapor sorption, or by gas liquid chromatography (glc). After correction for the free volume and for the combinatorial contributions (this last usually calculated in terms of segment fracctions using the Flory-Huggins equations [4,5]) the interactional contribution and the $x_{12}$ parameter are obtained. Both experimental approaches, but more frequently the calorimetric one, have been profusely employed to study hydrocarbon mixtures $[3,6]$.

It is not surprising that the behavior of real systems deviates from the predictions of Flory's semiempirical approach. Flory himself discovered that $X_{12}$ parameters obtained by fitting to experimental $\mathrm{H}^{\mathrm{E}}$ were larger than those obtained when fitting was made to $\mathrm{G}^{\mathrm{E}}[2,7]$. Patterson and collaborators advanced the idea that the discrepancies stem from theory's neglect of liquid structure; their arguments were supported on Rayleigh scattering measurements of Bothorel et al $[8,9]$, and were latter reinforced with numerous calorimetric results on carefully selected systems [10-12]. Short range orientational order, that can be thought as a partial alignment of neighboring segments or even of whole molecules, would be present in liquids formed from long non-branched molecules; this order is destroyed or replaced by weaker correlations on mixing with molecules of more globular shape, giving rise to positive contributions both to $\mathrm{H}^{\mathrm{E}}$ and $\mathrm{S}^{\mathrm{E}}$. Since $\mathrm{H}^{\mathrm{E}}$ and $\mathrm{TS}^{\mathrm{E}}$ are almost equal an enthalpy-entropy compensation occurs during the process, that is characterized by small contributions to $\mathrm{G}^{\mathrm{E}}$. Furthermore, order would be expected to decrease as the temperature raises, and its contributions to all the excess properties should become smaller.

A new contribution related with liquid structure was detected when the number of available experimental results increased. Important differences were found among the mixing enthalpies of a given normal alkane with a group of isomeric branched alkanes for which Rayleigh scattering indicated the same decrease in order during mixing; differences in $\mathrm{H}^{\mathrm{E}}$ correlated with differences in the branched alkanes molar volumes [13,14]. The same type of correlation was latter found between mixing entropies (corrected for combinatorial and free volume contributions) and molar volumes [15]. A lower molar volume is associated with a higher crowding of groups within the molecule, i.e. with steric hindrance to the free rotation of groups; negative enthalpy and entropy contributions occur on mixing rigid molecules with molecules freer in rotation, as normal alkanes, through mechanisms yet not known but that could be related to a coupling of the modes of both types of molecules that results in an increase of order in the solution.

Delmas et al. [16], using calorimetry, found that the enthalpy of mixing PIB with alkanes at low polymer concentration is negative. Flory and collaborators $[17,18]$ suggested that this behavior could be accounted for a combination of a negative free volume contribution 
and a small positive term that the authors attributed to interchange of neighbor species in contact; their prediction for the PIB+n-pentane system was a strong concentration dependence of the $\kappa^{*}$ parameter (i.e., the reduced excess enthalpy calculated on a segment fraction basis), which was negative through most of the range but reached +0.2 at the glc condition of polymer segment fraction $\varphi_{2}=1$.

In contradiction with these predictions glc measurements by Hammers and de Ligny [19] resulted in negative $\kappa^{*}$ 's for a group of PIB+alkane systems that included n-pentane. Negative values of $\kappa^{*}$ at several concentrations were also obtained by Gaecklé et al. [20] for the system PIB+n-pentane using calorimetry; concentration dependence was negligible so that it would be negative at $\varphi_{2}=1$.

Leung and Eichinger [21,22] employed the glc method to study the mixing of PIB with hydrocarbons; their residual chemical potentials at $25^{\circ} \mathrm{C}, \chi^{*}$, were very near to those obtained by extrapolating vapor sorption results to infinite dilution of the hydrocarbon, and the $x_{12}$ parameters calculated from $\chi^{*}$ differed by less than $1.2 \mathrm{J.cm}^{-3}$ from those calculated by Flory from integral heats of mixing. The values of $\chi^{*}$ for normal alkanes fell markedly with increase of temperature; hence the $\kappa^{*}$ parameters were large, between +0.6 and +0.8 .

Hammers and de Ligny injected the solutes in the liquid form, and their sample sizes were large, about $1 \mu \mathrm{mol}$, obtaining skewed peaks whose retention volumes decreased with mean flowrate; both deleterious effects disappeared above $100^{\circ} \mathrm{C}$. Smaller sample sizes were used by Leung and Eichinger, about $0.05 \mu \mathrm{mol}$ in the vapor form, and no dependence of the fully corrected retention volumes from flow rate was detected; however their peaks were skewed, a fact that the authors attributed to instrumental causes. The polymers employed in both chromatographic studies had a viscosity average molecular weight of $4 \times 10^{4}$; results could be affected by poor equilibration in the column due to slow diffusion of the vapours in PIB. This by no means explains the reasons why $\kappa^{*}$ parameters with opposite sign were obtained by both groups of workers.

The study of PIB + hydrocarbon mixtures by the glc method is taken up again in the present paper with the aim of settling some of the aforementioned discrepancies. A PIB specimen with a molecular weight markedly lower from those employed in former studies was used in order to minimize eventual diffusional effects; sample sizes were the smallest compatible with instrumental noise and dead volumes between column and detector were minimized. Results for tweny-four hydrocarbons, most of them normal and branched alkanes, were obtained at five temperatures within the interval $35-65^{\circ} \mathrm{C}$. The choice of the solutes was dictated by our interest in studying the effects of branching on the excess properties; measurements were performed at several temperatures in the hope that, in spite of known restrictions of the glc method for the measurement of excess enthalpies, the most important tendencies could be detected.

\section{EXPERIMENTAL SECTION}

Materials and columns. PIB was a gift from Polibutenos Argentinos SA; GPC analysis resulted in $\bar{M}_{n}=2300, \bar{M}_{W} / \bar{M}_{n}=1.45$, and less than $1 \%$ by weight of molecules 
with $M_{n}<500$. The polymer was coated on Chromosorb P AW DMCS 60/80 from a solution in n-hexane (Mallinckrodt p.a.) in a rotary evaporator, under a slow nitrogen flow. Coated support contained $9.95_{4} \%$ by weight of PIB and was packed into $0.43 \mathrm{~cm}$ i.d. and 1-2 m in lenght stainless steel tubes; columns were kept overnight at $90^{\circ} \mathrm{C}$ with $5-10 \mathrm{ml} / \mathrm{min}$ of nitrogen flow rate before using. Hydrocarbons of several origins, more than $99 \%$ pure, were used without further purification

Apparatus and procedure. Measurements were performed with a home assembled apparatus, in which column temperature was controlled to better than $\pm 0.05^{\circ} \mathrm{C}$ by immersion in a water bath. Nitrogen, successively passed through a molecular sieves trap (Davidson 5A), a Brooks 8606 pressure regulator, a Brooks 8743 flow controller and a $2 \mathrm{~m}$ x 1/8" o.d. copper tube immersed in the column bath, was used as the carrier gas. Inlet pressures were measured by means of a mercury manometer at a point between the copper coil and a Swagelok 1/4" s.s. "T"; one branch of this last was connected to the column and the remaining branch was provided with a septum through which solute vapors were injected by means of Hamilton microsyringes, applying the headspace sampling technique. Eluates were detected with a Hewlett-Packard 5750 FID and electrometer; signals were fed to a Hewlett-Packard 3396A integrator. Flow rates ranging between 20 and $50 \mathrm{ml} / \mathrm{min}$ were measured by means of a water jacketted soap film flowmeter.

Sample sizes were always smaller than $0.05 \mu \mathrm{mol}$; highly symmetrical peaks were obtained, indicating that Henry's law conditions had been attained. Solute vapors and a small methane sample were simultaneously injected; net retention times (in no instance smaller than $2 \mathrm{~min}$ ) were measured to $\pm 0.001 \mathrm{~min}$ between the times for the solute $\left(t_{R}\right)$ and the methane $\left(\mathrm{t}_{\circ}\right)$ peaks maxima. Retention times for groups of 3-6 solutes were measured at five temperatures equally spaced between 35 and $65^{\circ} \mathrm{C}$; measurements at each temperature were made at least in quadruplicate. Measurements for a given solute, repeated after an interval of several days, differred from the original ones in less than $0.5 \%$.

Density of the PIB sample was measured at ten temperatures between 23 and $65^{\circ} \mathrm{C}$, by means of a $25 \mathrm{ml}$ pycnometer that had been carefully calibrated through the same temperature interval, and least squares fitted to the equation

$\rho_{2}=0.9166-5.470 \times 10^{-4} \mathrm{t}$

where $t$ is the temperature in degrees Centigrade. Eq. (1) is accurate to $\pm 1.7 \times 10^{-4}$ in the temperature range of the measurements; the fit does not improve by using a second degree polynomial. The thermal expansion coefficient derived from eq.(1) is (in $\mathrm{deg}^{-1}$ )

$\alpha_{2}=5.96 \times 10^{-4}+3.74 \times 10^{-7} \mathrm{t}$

\section{RESULTS}

Specific retention volumes, $\mathrm{V}_{\mathrm{g}}^{\circ}$, were calculated from the relation [23]

$V_{g}^{0}=j\left(F_{f} / w\right)\left(273.15 / T_{f}\right)\left(t_{R}-t_{o}\right)\left(P_{o}-p_{w}\right) / P_{o}$ 
where $\mathrm{j}$ is the James-Martin carrier gas compressibility correction factor, $w$ is the mass of PIB within the column, $F_{f}$ is the carrier flow rate measured at the temperature $T_{f}$ and pressure $P_{0}$ of the flowmeter, and $p_{w}$ is the water vapor pressure at $T_{f}$. Measurements at $50^{\circ} \mathrm{C}$ for a selected group of solutes were performed at several flow rates between 17 and $55 \mathrm{ml} / \mathrm{min}$; $\mathrm{V}_{\mathrm{g}}^{\circ}$ results, as calculated by eq(3), were coincident within experimental error.

Equation (4) was used to calculate the $\chi^{*}$ parameters [24]

$\chi^{*}=\ln \left(273.15 R v_{2}^{*} / p_{1}^{0} V_{g}^{0} V_{1}^{*}\right)-1+V_{1}^{*} / \bar{M}_{n} v_{2}^{*}-p_{1}^{0}\left(B_{11}-V_{1}\right) / R T+\left(2 B_{13}-\bar{V}_{1}^{\infty}\right) P_{0} J_{3}^{4} / R T$

where $p_{1}^{\circ}, V_{1}$ and $\bar{V}_{1}^{\infty}$ are the solute vapor pressure, liquid-state molar volume and partial molar volume at infinite dilution in the polymeric solvent (approximated by $V_{1}$ in the present paper), respectively; $B_{11}$ and $B_{13}$ are the second virial coefficients for the solute-solute and solute-nitrogen interactions in the vapor phase, and $J_{3}^{4}$ is a function of the columns inlet and outlet pressures [23].

The polymer characteristic specific volume, $v_{2}^{*}$, and the solute characteristic molar volume , $V_{1}^{*}$, are obtained from pure component volumetric data, as detailed by Flory and collaborators $[1,2]$. Vapor pressures were calculated by using the equation of Antoine with the coefficients compiled by Dreisbach [25]; for the molar volumes the density data of Orwoll and Flory [7] or those given by Timmermans [26] were used. Second virial coefficients were computed by means of the corresponding states equation of McGlashan and Potter [27], using critical constants given by Kudchadker et al. [28] and by Reid et al. [29]. The solutes characteristic parameters in terms of the Flory state equation theory $\left(V_{1}^{*}, T_{1}^{*}\right.$ and $\left.p_{1}^{*}\right)$, calculated from density, thermal expansion coefficient and thermal pressure coefficient at $25^{\circ} \mathrm{C}$, have been tabulated in former publications [30,31]. The polymer characteristic parameters $v_{2}^{*}$ and $T_{2}^{*}$ were calculated by using equations (1) and (2); our results at two temperatures are compared in Table I with those obtained by Eichinger and Flory [32] for a higher molecular weight specimen. Differences in the properties of both polymers are in the sense that could be qualitatively predicted from their molecular weights; values of $v_{2}^{*}$, however, differ by less than $0.5 \%$.

\section{TABLE I}

Equation of State Data and Characteristic Parameters for Two PIB Specimens of Different Molecular Weight

\begin{tabular}{|c|c|c|c|c|}
\hline & \multicolumn{2}{|c|}{$\bar{M}_{v}=4 \times 10^{4} \mathrm{a}$} & \multicolumn{2}{|c|}{$\bar{M}_{\mathrm{h}}=2300^{b}$} \\
\hline & $25^{\circ} \mathrm{C}$ & $50^{\circ} \mathrm{C}$ & $25^{\circ} \mathrm{C}$ & $50^{\circ} \mathrm{C}$ \\
\hline$\rho_{2} / \mathrm{g} . \mathrm{cm}^{-3}$ & 0.9169 & 0.9042 & 0.9029 & 0.8893 \\
\hline$\alpha_{2} / \mathrm{deg}^{-1}$ & 5.55 & 5.60 & 6.06 & 6.15 \\
\hline$\tilde{v}_{2}$ & 1.1488 & 1.1610 & 1.1609 & 1.1752 \\
\hline$v_{2}^{*} / \mathrm{cm}^{3} \cdot \mathrm{g}^{-1}$ & 0.9493 & 0.9525 & 0.9540 & 0.9562 \\
\hline $\mathrm{T}_{2}^{*} / \mathrm{K}$ & 7577 & 7726 & 7134 & 7250 \\
\hline
\end{tabular}


Values of $\chi^{*}$ at each of the five experimental temperatures were calculated using mean values for not less than two independent measurements of $v_{0}^{\circ}$. Our estimation of the uncertainty on $\chi^{*}$ is about \pm 0.01 , resulting from the quoted dispersion in $V_{o}^{\circ}$ plus contributions of the remaining terms in eq(4). Partial molar residual enthalpies were calculated by means of the equation

$\bar{H}_{1}^{R}=R\left\{\partial \chi^{*} / \partial(1 / T)\right\}$

assuming $\bar{H}_{1}^{R}$ constant within the $35-65^{\circ} \mathrm{C}$ interval. No trend could be detected for the residuals, this indicating that the error of the model (i.e., assuming a temperature independent excess enthalpy) is overcome by the experimental error. The uncertainties on $\bar{H}_{1}^{R}$, as estimated from the least squares fit, range between \pm 100 and $\pm 250 \mathrm{~J} / \mathrm{mol}$. Therefore, only a semiquantitative significance can be assigned to the values of the reduced partial molar residual enthalpy and entropy, calculated by means of the relations $\kappa^{*}=\bar{H}_{1}^{R} / R T$ and $\bar{S}_{1}^{R} / R=\kappa^{*}$ $\chi^{*}$, respectively. Results for $\chi^{*}, \kappa^{*}$ and $\bar{S}_{1}^{R} / R$ at $50^{\circ} \mathrm{C}$ have been gathered in Table II. All the alkanes' $\mathbf{K}^{*}$ values are positive, in coincidence with the findings of Leug and Eichinger; our results, however, are considerably smaller than theirs.

\section{DISCUSSION}

According to the Flory state equation theory the solute residual chemical potential and partial molar enthalpy at infinite dilution in the polymer are given by the following equations:

$\chi^{*} R T=p_{1}^{*} V_{1}^{*}\left\{3 \tilde{T}_{1} \ln \left[\left(\tilde{v}_{1}^{1 / 3}-1\right) /\left(\tilde{v}_{2}^{1 / 3}-1\right)\right]+\tilde{v}_{1}^{-1}-\tilde{v}_{2}^{-1}\right\}+X_{12} V_{1}^{*} / \tilde{v}_{2}$

$\kappa^{*} R T=p_{1}^{*} V_{1}^{*}\left[\left(\alpha_{2} T / \tilde{v}_{2}\right)\left(T_{2}^{*} / T_{1}^{*}-1\right)+\tilde{v}_{1}^{-1}-\tilde{v}_{2}^{-1}\right]+X_{12} V_{1}^{*}\left(1+\alpha_{2} T\right) / \tilde{v}_{2}$

where reduced volumes and temperatures are defined by $\tilde{v}_{i}=v_{i} / v_{i}^{*}$ and $\bar{T}_{i}=T / T_{i}^{*}$, respectively. The first term in equations (6) and (7) represents the contribution from free volume effects. In Flory's original model the second term in each of these equations was identified with contact interaction contributions only, but in Patterson's scheme they could equally well represent contributions from order, or from steric hindrance, or eventually from a combination of the three effects. Furthermore, Patterson and collaborators have denied any importance to interactional contributions in alkane mixtures; as a matter of fact much of the work done in this area during the last twenty years was devoted to the identification of the origins of these contributions. Such an assignment is not a direct or simple matter in the present circumstances, as we pass to discuss. 
Reduced Residual Chemical Potentials $\left(\chi^{*}\right)$, Reduced Partial Molar Residual Enthalpies $\left(\kappa^{*}\right)$ and and Reduced Partial Molar Residual Entropies $\left(\bar{S}_{1}^{R} / R\right.$ ) for Hydrocarbons at Infinite Dilution in Polyisobutylene at $5^{\circ} \mathrm{C}$.

\begin{tabular}{|c|c|c|c|}
\hline SOLUTE & $\chi^{*}$ & $\mathbf{K}^{*}$ & $\bar{S}_{1}^{R} / R$ \\
\hline n-Pentane & 0.707 & 0.28 & -0.43 \\
\hline n-Hexane & 0.623 & 0.17 & -0.50 \\
\hline 2-Methylpentane & 0.648 & 0.32 & -0.33 \\
\hline 3-Methylpentane & 0.605 & 0.32 & -0.29 \\
\hline 2,2-Dimethylbutane & 0.678 & 0.56 & -0.12 \\
\hline 2,3-Dimethylbutane & 0.606 & 0.49 & -0.12 \\
\hline n-Heptane & 0.570 & 0.13 & -0.44 \\
\hline 2-Methylhexane & 0.589 & 0.28 & -0.31 \\
\hline 3-Methylhexane & 0.558 & 0.30 & -0.26 \\
\hline 2,2-Dimethylpentane & 0.625 & 0.57 & -0.05 \\
\hline 2,3-Dimethylpentane & 0.504 & 0.45 & -0.06 \\
\hline 2,4-Dimethylpentane & 0.629 & 0.38 & -0.25 \\
\hline n-Octane & 0.518 & 0.11 & -0.41 \\
\hline 2-Methylheptane & 0.535 & 0.25 & -0.29 \\
\hline 4-Methylheptane & 0.510 & 0.26 & -0.25 \\
\hline 2,2-Dimethylhexane & 0.570 & 0.40 & -0.17 \\
\hline 2,5-Dimethylhexane & 0.572 & 0.35 & -0.22 \\
\hline $\begin{array}{l}2,2,4- \\
\text { Trimethylpentane }\end{array}$ & 0.563 & 0.52 & -0.04 \\
\hline $\begin{array}{l}2,3,4- \\
\text { Trimethylpentane }\end{array}$ & 0.451 & 0.49 & -0.04 \\
\hline n-Nonane & 0.487 & 0.13 & -0.36 \\
\hline Cyclohexane & 0.478 & 0.55 & 0.08 \\
\hline Benzene & 0.818 & 0.95 & 0.14 \\
\hline Toluene & 0.665 & 0.92 & 0.25 \\
\hline Ethylbenzene & 0.641 & 0.87 & 0.23 \\
\hline
\end{tabular}

In order to validate our results it is necessary to mention that our $\chi^{*}$ results are smaller than those obtained by Leung and Eichinger [21,22]; differences drop from $0.08-0.15$ at $25^{\circ} \mathrm{C}$ (extrapolation of our data) to $0.04-0.10$ at $65^{\circ} \mathrm{C}$. These discrepancies have their origin in the different volumetric behavior displayed by the polymer employed by Leung and Eichinger and that used in the present paper; when the free volume contributions are deducted from the experimental $\chi^{*}$ by using eq(6) and the data in Table I, coincident residual contributions are obtained from both sets of results. 
Values of $x_{12}$ calculated from $\chi^{*}(\mathrm{eq}(6))$ decrease linearly with temperature (0.01-0.05 $\mathrm{J} . \mathrm{cm}^{-3} \cdot \mathrm{K}^{-1}$ for alkanes and $0.02-0.08 \mathrm{~J} . \mathrm{cm}^{-3} \cdot \mathrm{K}^{-1}$ for aromatics and cyclohexane). On the other side $X_{12}$ parameters obtained from $x^{*}$ by means of eq( 7$)$ are between two and four times larger than those obtained from $\chi^{*}$. These are very large differences, and are displayed by all the systems studied in the present work; therefore they cannot be attributed to the uncertainties inherent in the calculation of the excess enthalpies from experimental activity coefficients. This is the type of behavior that could be expected in case orientational order exists in PIB, an hypothesis difficult to sustain on account of the numerous methyl side groups in the polymer molecule. However similar behavior was detected in chromatographic studies involving hydrocarbons and stationary phases for which it would be rather bold to assume order, as tetra-n-amyltin [31]. It may be presumed that some degree of ordering could exist in almost any liquid suitable to be employed as stationary phase in glc, and that the effects of this order should be specially noticeable under the conditions of extremely low concentration prevailing in chromatographic measurements; the first molecules to get into solution shall find the stationary phase in its more ordered state, promoting the largest order perturbations. The solid support surface, on the other side, may well induce some type of ordering of the stationary phase molecules.

Flory et al. [18] found that a smooth curve was obtained when $\mathrm{X}_{12}$ values for PIB + normal alkane systems (calculated from enthalpies of mixing) were plotted against the reciprocal of the number of carbon atoms in the alkane chain. This was attributed by the authors to contact interactions and, since $x_{12}$ increases with the proportion of methyl groups in the alkane molecule, important chemical differences have to be admitted between this last type of group and the highly crowded methyl groups that constitute, almost completely, the surface of the polymer molecule. Delmas [33] suggested that this effect could have its origin in an overestimation of the free volume term by the Flory theory for systems with large differences in expansion coefficient. The value of $\alpha_{2}$ for our low molecular weight PIB is about $10 \%$ higher than those of polymers used by former authors, and it was seemingly interesting to check whether the effect persisted or not.

Following this line of argument $X_{12}$ values calculated from $\kappa^{*}$ have been plotted in Figure 1a against the fraction of methyl type surface in the alkane molecules, $\theta_{e 1}$, calculated as the ratio of the number of hydrogen atoms on methyl groups to the total number of hydrogens in the molecule. There is a strong correlation between both variables; a least squares analysis performed under the assumption of a first order linear relationship results in a correlation coefficient of 0.83 and an ordinate that does not differ significantly from zero. The mean of the residuals is $2.3 \mathrm{~J} . \mathrm{cm}^{-3}$, in coincidence with our estimation of the uncertainty on $x_{12}$ parameters calculated from $\kappa^{*}$. On the other side no correlation can be detected between values of $x_{12}$ calculated from $\chi^{*}$ at $50^{\circ} \mathrm{C}$ and $\theta_{\mathrm{e} 1}$, as shown in Figure $1 \mathrm{~b}$; individual points are scattered

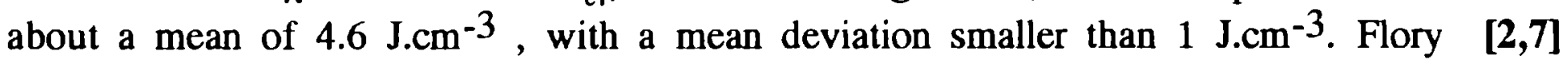
suggested that contact interaction contributions to the excess properties were not only of enthalpic nature; it may be expected that entropy shall also be affected. To account for this effect he substituted $X_{12}$ in eq(6) for $X_{12}^{H}-Q_{12} T v_{2}$, where $X_{12}^{H}$ and $Q_{12}$ are temperature and volume independent terms, associated with enthalpic and entropic effects of contact interactions; differentiation of so modified eq (6) results in eq (7), but with $x_{12}$ replaced by $X_{12}^{H}$. The results displayed in Figures $1 \mathrm{a}$ and $1 \mathrm{~b}$ suggest the existence of positive contributions from contact interaction, of similar importance both in $\mathrm{H}^{\mathrm{E}}$ and in $\mathrm{TS} E$, that 


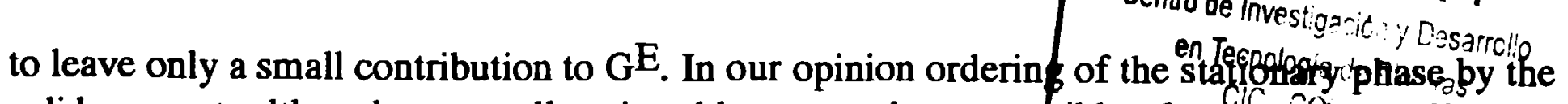
solid support, although not totally rejectable, cannot be respons ste of $\$ 0$ potorious effects; a silanized solid support was employed and, according with its specifio-sufface ! area, (abput $4 \mathrm{~m}^{2} \cdot \mathrm{g}^{-1}$ ) and the stationary phase concentration, the mean thickness of the PIB film was about $300 \mathrm{~A}$.

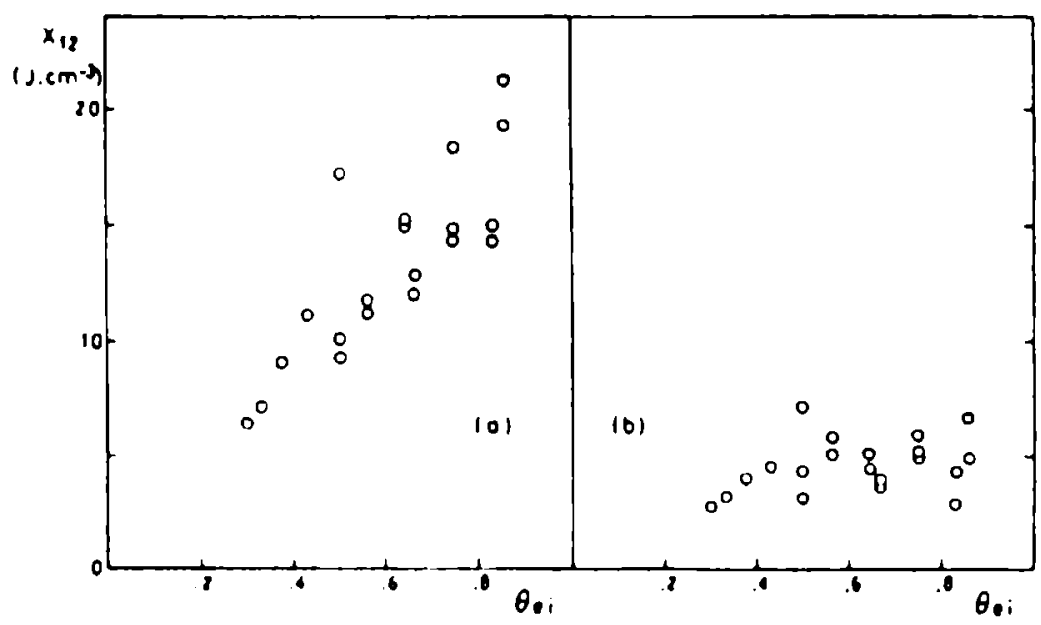

Fig. 1.- Binary Flory interaction parameters $\left(X_{12},{\mathrm{~J} . \mathrm{cm}^{-3}}^{-3}\right.$ for PIB + alkane mixtures against the fraction of hydrogen atoms on methyl groups $\left(\theta_{\mathrm{e} 1}\right)$. (a) $\mathrm{X}_{12}$ calculated from $\kappa^{*}$

(b) $X_{12}$ calculated from $\chi^{*}$

$\chi^{*}$ values for alkanes at $50^{\circ} \mathrm{C}$ are plotted against molar volumes in Figure 2. First to be noted is the smooth downfall of the normal alkane points; second, straight lines can be drawn through points corresponding to isomeric solutes. The slopes of those drawn in the figure for hexanes, heptanes and octanes are coincident and the correlation coefficients are higher than 0.98 in the three cases. These trends could be associated with steric hindrance effects; however there are several reasons to disregrad that possibility. First, $\kappa^{*}$ values do not change regularly with molar volumes within a given isomers group. Second, since PIB segments are highly sterically hindered, the larger effects (negative contributions to $\mathrm{H}^{\mathrm{E}}, \mathrm{S}^{\mathrm{E}}$ and $\mathrm{G}^{\mathrm{E}}$ ) should be observed on mixing with isomers of larger molar volume. Finally a plot of free volume contributions to $\chi^{*}$ against $V_{1}$ reproduces the principal characteristics of Figure 2, although a larger scatter of the points is observed; the quality of thermal pressure coefficient values of the branched alkanes, taken from different sources, can be the cause of this poorer correlation.

Solutions of aromatic hydrocarbons are markedly more endothermic than those of the alkanes; partial molar residual entropies, however, are positive for aromatics and negative for the alkanes. Since free volume contributions do not justify these differences, they must be attributed to their chemical dissimilarity. Interactional contributions to the reduced chemical potential, reduced partial molar enthalpy and entropy for $\mathrm{n}$-hexane, cyclohexane and benzene have been gathered in Table III; they were calculated using $X_{12}$ parameters obtained from residual enthalpies in eq (6) and (7). These results, that must be considered cautiously on account of their very indirect origin, indicate important differences between the three solutes. According with these numbers cyclohexane molecules are more strongly repelled by the PIB segments and are freer in their motions than those of $n$-hexane. PIB repulsion for benzene is yet stronger than that for cyclohexane, but no difference exists between the interactional partial molar entropy of both solutes. 
TABLE III

\section{Interactional Contributions to the Reduced Chemical Potential ( $\left.x_{\text {ind }}^{*}\right)$, Reduced Partial Molar Residual Enthalpy $\left(x^{\circ}\right.$ int) and Reduced Partial Molar Residual Entropy $\left(\bar{S}_{1}^{\text {, }} / \mathbf{R}_{\mathrm{ln}}\right)$.}

$\begin{array}{lccc}\text { Solute } & x_{\text {im }}^{\bullet} & \kappa^{\bullet} \text { int } & \bar{S}_{1}^{\text {R }} / R_{\text {lix }} \\ \text { n-Hexane } & 0.14 & 0.4 & 0.3 \\ \text { Cyclohexane } & 0.13 & 0.7 & 0.6 \\ \text { Benzene } & 0.47 & 1.1 & 0.7\end{array}$

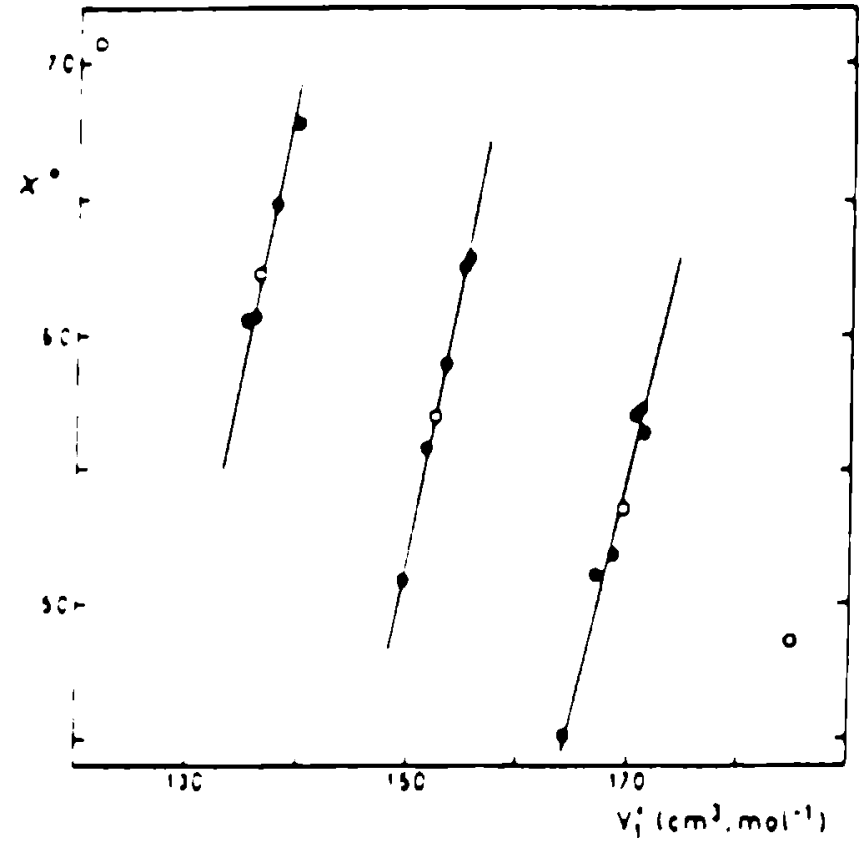

Fig. 2. - Infinite dilution residual chemical potentials of alkanes at $50^{\circ} \mathrm{C}\left(\chi^{*}\right)$ against their molar volumes $\left(\mathrm{V}_{1 .}\right)$. (o) Normal alkanes. (๑) Branched alkanes.

\section{ACKNOWLEDGEMENT}

This work was sponsored by CONICET (Consejo Nacional de Investigaciones Científicas y Técnicas de la República Argentina) and by CICPBA (Comisión de Investigaciones Científicas de la Provincia de Buenos Aires).

\section{REFERENCES}

[1] Flory P. J., Orwoll R. A. and Vrij, A.- J Am. Chem. Soc, 86, 3507, 3515 (1964).

[2] Eichinger B. E. and Flory P. J.- Trans. Faraday. Soc, 64, 2035 (1968).

[3] Patterson D.- J. Solution Chem, 23, 105 (1994). 
[4] Flory P. J.- J. Chem. Phys., 10, 51 (1942); ibid, 12, 425 (1944).

[5] Huggins M. L.- Ann. N. Y. Acad. Sci, 43, 9 (1942).

[6] Bhattacharyya S. N., Costas M. and Patterson D.- Fluid Phase Equil, 20, 27 (1985).

[7] Orwoll R. A. and Flory P. J.- J. Am. Chem. Soc. 89, 6814, 6822 (1967).

[8] Bothorel P., Clement C. and Maraval P.- Compt. Rend, 264, 658 (1967).

[9] Quinones H. and Bothorel P.- Compt. Rend., 277, 133 (1973).

[10] Lam V. T., Picker P., Patterson D. and Tancrède P.- J. Chem. Soc. Faraday II, 70, 1465 (1974).

[11] Tancrède P., Patterson D. and Lam V. T.- J. Chem. Soc. Faraday II, 71, 985 (1975).

[12] Barbe M. and Patterson D.- J. Phys. Chem, 82, 40 (1978).

[13] Tancrède P., Bothorel P., de St. Romain P. and Patterson D.- J. Chem. Soc. Faraday II, 73, 15 (1977)

[14] de St. Romain P., Van H. T. and Patterson D.- J. Chem. Soc. Faraday I, 75, 1700 (1979).

[15] Barbe M. and Patterson D.- J. Solution Chem, 9, 753 (1980).

[16] Delmas G., Patterson D. and Somcynsky T.- J. Polym. Sci., 57, 79 (1962).

[17] Eichinger B. E. and Flory P. J.- Trans. Faraday Soc, 64, 2053, 2061, 2066 (1968).

[18] Flory P. J., Ellenson J. L. and Eichinger, B. E.- Macromolecules, 1, 279 (1968).

[19] Hammers W. E. and de Ligny, C. L.- Rec. Trav. Chim, 90, 912 (1971).

[20] Gaecklé D., Kao W. P., Patterson D. and Rinfret M.- J. Chem. Soc. Faraday I, 69, 1849 (1973).

[21] Leung Y. K. and Eichinger B. E.- J. Phys. Chem, 78, 60 (1974).

[22] Leung Y. K. and Eichinger B. E.- Macromolecules, 7, 685 (1974).

[23] Conder J.R. and Young C.L.- Physicochemical Measurements by Gas-Liquid Chromatography, Wiley, New York (1979).

[24] Patterson D., Tewari Y. B., Schreiber H. P. and Guillet.- Macromolecules, 4, 356 (1971). 
[25] Dreisbach R. R.- Physical Properties of Chemical Componunds. Advances in Chemistry Series, 15 (1955); 22 (1959); 29 (1961), American Chemical Society, Washington, DC.

[26] Timmermans J.- Physical Constants of Pure Organic Compounds; Vol. I (1950); Vol. II (1965), Elsevier, New York.

[27] McGlashan M. L. and Potter J. B.- Proc. Roy. Soc. A, 267, 478 (1967).

[28] Kudchadker A. P., Alani G. H. and Zwolinski J. B.- Chem. Rev., 68, 659 (1968).

[29] Reid R. C., Prausnitz J. M. and Poling, B. E.- The Properties of Gases and Liquids; McGraw-Hill, Singapore, (1988).

[30] Castells R. C. and Castells C.B.- J. Solution Chem, 21, 129 (1992).

[31] Castells R. C. and Castells C. B.- J. Solution Chem., 24, 285 (1995).

[32] Eichinger B. E. and Flory P. J.- Macromolecules, 1, 285 (1968).

[33] Phuong-Nguyen H. and Delmas G.- Macromolecules, 12, 740, 746 (1979). 